\title{
Transthoracic Echocardiography with Doppler Tissue Imaging predicts weaning failure from mechanical ventilation: evolution of the left ventricle relaxation rate during a spontaneous breathing trial is the key factor in weaning outcome
}

Sébastien Moschietto ${ }^{1 *}$, Denis Doyen², Ludovic Grech¹, Jean Dellamonica ${ }^{1}$, Hervé Hyvernat ${ }^{1}$ and Gilles Bernardin ${ }^{1}$

\begin{abstract}
Introduction: There is growing evidence to suggest that transthoracic echocardiography (TTE) should be used to identify the cardiac origin of respiratory weaning failure. The aims of our study were: first, to evaluate the ability of transthoracic echocardiography, with mitral Doppler inflow E velocity to annular tissue Doppler Ea wave velocity (E/Ea) ratio measurement, to predict weaning failure from mechanical ventilation in patients, including those with atrial fibrillation; and second, to determine whether the depressed left ejection fraction and/or diastolic dysfunction participate in weaning outcome.
\end{abstract}

Methods: The sample included patients on mechanical ventilation for over 48 hours. A complete echocardiography was performed just before the spontaneous breathing trial (SBT) and 10 minutes after starting the SBT. Systolic dysfunction was defined by a left ventricle ejection fraction under $50 \%$ and relaxation impairment by a protodiastolic annulus mitral velocity Ea under or equal to $8 \mathrm{~cm} / \mathrm{second}$.

Results: A total of 68 patients were included. Twenty failed the weaning process and the other 48 patients succeeded. Before the SBT, the E/Ea ratio was higher in the failed group than in the successful group. The E/Ea measured during the SBT was also higher in the failed group. The cut-off value, obtained from receiver operating characteristics (ROC) curve analysis, to predict weaning failure gave an E/Ea ratio during the SBT of 14.5 with a sensitivity of $75 \%$ and a specificity of $95.8 \%$. The left ventricular ejection fraction did not differ between the two groups whereas Ea was lower in the failed group. Ea increased during SBT in the successful group while no change occurred in the failed group.

Conclusions: Measurement of the E/Ea ratio with TTE could predict weaning failure. Diastolic dysfunction with relaxation impairment is strongly associated with weaning failure. Moreover, the impossibility of enhancing the left ventricle relaxation rate during the SBT seems to be the key factor of weaning failure. In contrast, the systolic dysfunction was not associated with weaning outcome.

\footnotetext{
* Correspondence: sebastien.moschietto@orange.fr

1 Medical Intensive Care Unit, Archet I University Hospital, 151 route Antoine

de Ginestière, 06202, Nice, France

Full list of author information is available at the end of the article
} 


\section{Introduction}

Cardiogenic pulmonary edema has been recognized as a frequent cause of weaning failure [1-3]. The definitive diagnosis remains difficult; in this situation right heart catheterization was proposed as the reference tool $[3,4]$. Lemaire et al. demonstrated that a spontaneous breathing trial (SBT) induced an elevation in the left ventricular filling pressure (LVFP), which plays a key role in weaning failure [3]. Since the introduction of a pulmonary artery catheter remains an invasive and potentially harmful procedure, there is growing evidence to suggest that transthoracic echocardiography (TTE) should be used to identify the cardiac origin of respiratory weaning failure [4]. Tissue Doppler is a novel technique that directly measures myocardial velocities $[5,6]$. The early diastolic mitral annulus velocity (Ea) has been shown to be a relatively load independent measure of myocardial relaxation [6-8]. When Ea is combined with pulsed Doppler mitral flow in early diastole $\mathrm{E}$, the resulting $\mathrm{E} / \mathrm{Ea}$ ratio closely correlated with the measured invasive LVFP [6,9]. Lamia et al. showed that the combination of E/A mitral inflow and E/Ea at the end of a SBT predicted an increase in the LVFP, with a good sensitivity and specificity, in a selected population of patients who were difficult to wean [4]. More recently, Caille et al. found a significantly higher E/Ea ratio at baseline in failed patients [10]. These studies excluded patients with atrial fibrillation, which represent 20 to $30 \%$ of patients hospitalized in intensive care units [11]. Nevertheless, despite this arrhythmia, the LVFP could be assessed accurately with measurement of the E/Ea ratio [12].

The primary objective of our study was to test the ability of the mitral E/Ea ratio, measured at baseline and shortly after initiation of SBT, to determine the risk of weaning failure in a non-selected population, including patients with atrial fibrillation. The second aim was to determine whether the depressed left ejection fraction and/or diastolic dysfunction participated in weaning outcome.

\section{Materials and methods}

This observational prospective study was conducted from November 2009 to April 2011 in a 10-bed medical intensive care unit. No change of standard care was introduced for the needs of this study, which was, therefore, accepted as a descriptive study by the clinical research committee of the university hospital of Nice, in accordance with the ethical standards laid down in the 1964 Declaration of Helsinki. Because it is a descriptive study, written informed consent was waived but all patients involved in our study or their next of kin were informed and accepted to participate.

We screened patients under mechanical ventilation for more than 48 hours before they were considered ready to undergo an initial SBT. Patients were included if they met the following criteria: improvement of the underlying cause of acute respiratory failure, body temperature $<39^{\circ} \mathrm{C}$, hemoglobin level > 7G/dl, $\mathrm{PaO} 2>60 \mathrm{mmHg}$, FIO2 < 40\%, positive end expiratory pressure (PEEP) under or equal to $8 \mathrm{~cm} \mathrm{H} 2 \mathrm{O}$, respiratory rate less than 35 breathes/minute, systolic arterial pressure $>90$ $\mathrm{mmHg}$ and $<160 \mathrm{mmHg}$ without need for vasoactive drugs, no sedation and a stable neurological status [13].

Non-inclusion criteria included tracheostomy, active neuromuscular disease, pregnant women, a poor echocardiography window, heart rate faster than 140 beats per minute at baseline, and patients with atrioventricular conduction abnormalities. Patients with severe mitral regurgitation, mitral stenosis or a prosthetic mitral valve were also excluded because E/Ea had not been validated in such patients for evaluation of LVFP.

\section{Spontaneous breathing trial}

The SBT lasted one hour and consisted of a low pressure support trial at $7 \mathrm{~cm} \mathrm{H} 2 \mathrm{O}$ without PEEP [14]. Patients were considered to have failed the SBT if they developed any of the following signs during the onehour SBT [15]: respiratory frequency $>35$ breaths per minute, arterial oxygen saturation $<90 \%$, heart rate $>$ 140 beats per minute or sustained increase or decrease in blood pressure with systolic arterial pressure $>200$ or $<80 \mathrm{mmHg}$, diaphoresis and signs of distress. The time of occurrence of these signs after starting the SBT was noted. Patients who succeeded the SBT were extubated. The attending physician in charge of the patient had no access to the TTE findings. Failure of the weaning process was defined as a failed SBT or the need for reintubation within 48 hours following extubation. Diagnosis of weaning failure was carried out by two intensivists blinded to the TTE report. Based on clinical and radiological findings they confirmed or excluded the diagnosis of cardiogenic pulmonary edema. The following signs or information were used and were assumed to be suggestive of weaning induced pulmonary edema: previous history of heart disease, exclusion of other causes of respiratory failure, early onset of respiratory distress after suppression of PEP, the presence of frothy secretions and bilateral crackles and onset of newer bilateral infiltrates on chest $\mathrm{x}$-ray.

\section{Bedside monitoring}

During assisted mechanical ventilation, the level of pressure support (AI), PEEP, the patient's respiratory rate (RR), tidal volume (VT) and the RR/VT ratio [16] were recorded just before initiation of the SBT. Arterial blood gas analysis was performed just before and at the end of the SBT. The heart rate, respiratory rate, blood pressure, 
pulsed oximetry and consciousness were monitored throughout the SBT.

\section{Bedside echocardiography}

TTE was performed using a Vivid 7 General Electric ${ }^{\circledR}$ healthcare Amersham United Kingdom just before the SBT, and 10 minutes after starting the SBT. The left ventricular ejection fraction (LVEF) was assessed using Simpson's method. Pulsed-wave Doppler analysis of mitral inflow allowed measurement of the $\mathrm{E}$ wave velocity and the E wave deceleration time (DTE). Pulsed wave Doppler tissue imaging (DTI) was performed at transducer frequencies of $3.5 \mathrm{MHz}$ with an as possible optimal gain, to obtain the best signal to noise ratio. The myocardial velocity was recorded using the DTI technique. The sample volume was placed at the junction of the left ventricular wall with the mitral annulus of the lateral myocardial segments from apical four-chamber views. Ea was measured and E/Ea was then calculated. The mean of three measurements was used for calculation. All the Doppler flow measurements were performed at the end of the expiratory period. In the case of atrial fibrillation, E/Ea was averaged over 10 cardiac cycles [12].

Systolic dysfunction was defined by a LVEF below $50 \%$. Relaxation impairment was confirmed by a velocity Ea below or equal to $8 \mathrm{~cm} / \mathrm{sec}$ [17]. Cardiac ischemia during SBT was identified by new left ventricular (LV) segmental wall motion abnormalities. All the echocardiographic examinations were performed by a cardiologist blinded to the clinical outcome.

\section{Statistical analysis}

Statistical analysis was performed using IBM SPSS ${ }^{\circledR}$ Software 19.0.0 Chicago, United states of America. Continuous variables were expressed as medians and interquartiles ( $25^{\text {th }}$ to $75^{\text {th }}$ percentile), and categorical variables as percentages. Categorical variables were analyzed with a Chisquare test or the Fisher's exact test. Continuous variables were compared using the U Man and Whitney or the Wilcoxon test as appropriate. Two-tailed $P$-values less than 0.05 were considered statistically significant. Receiver operating characteristics (ROC) curve analysis was performed to assess the ability of E/Ea to predict weaning failure. To examine inter-observer variability, a coinvestigator, blinded to the clinical information and to the results of the first investigator, examined 10 randomly selected Doppler mitral inflow and Doppler tissue images to determine $\mathrm{E} / \mathrm{Ea}$. Inter-observer variability was calculated as the difference between the values obtained by the two observers divided by the mean.

\section{Results}

From November 2009 to April 2011, 82 patients were screened, but 14 were excluded for the following reasons: suboptimal echocardiography images $(n=7)$, neuromuscular disease $(n=3)$, and tracheostomy $(n=4)$.

Sixty-eight patients were included. The reasons for intubation were septic shock $(n=20)$, cardiac arrest $(n$ $=5)$, cardiogenic pulmonary edema $(n=6)$, acute respiratory distress syndrome $(n=10)$, post-operative period $(n=7)$ pneumonia $(n=12)$ and coma $(n=8)$.

Twenty patients failed to wean. Sixteen patients failed the SBT, 14 patients with cardiogenic pulmonary edema and 2 with respiratory acidosis without hypoxemia. The cause of these two respiratory failures was under diagnosed ICU acquired weakness. These two patients underwent tracheotomy, one died in intensive care while the other one was delivered from mechanical ventilation four weeks later.

Four patients failed in the post extubation period. The time of occurrence of SBT failure was 24 minutes [17-33]. The reasons for extubation failure were septic shock $(n=2)$ and excessive bronchorrhea $(n=2)$.

Fifteen patients presented with atrial fibrillation (22.1\%) at the time of inclusion, among these 15 patients 9 (60\%) failed the SBT and all presented with weaning induced pulmonary edema. Six others patients succeeded the SBT and none needed re-intubation.

\section{Clinical characteristics}

Compared to the successful group, there was significant greater intensive care unit mortality in patients who failed the weaning process (35\% versus $8.3 \%, P=0.05$; Table 1). Diabetes mellitus was more frequent in the failed group (30\% versus $8.3 \%, P=0.05$; Table 1 ).

The LVEF did not differ significantly between groups, whereas the prevalence of left ventricular relaxation impairment was higher in the failed group (Table 1).

\section{Baseline characteristics}

Patients in the failed group had a higher respiratory rate, a lower VT and a higher RR/VT ratio (Table 2). Before $\mathrm{SBT}, \mathrm{Ea}$ was lower and E/Ea was higher in the failed group.

\section{Parameters measured during the SBT}

Ea was still lower and E/Ea higher in the failed group (Table 2). One patient in the failed group presented with myocardial ischemia during SBT, as attested by renewed septal dyskinesia

\section{Parameter changes during the SBT}

The SBT was accompanied by changes in the echocardiographic index (Figures 1 and 2). A significant increase in the E/Ea ratio was observed in the failed group (13.4 (8.4 to 16.3 ) versus 15.7 (13.4 to 21.1 ), $P=$ $0.004)$, while no variation was observed in the successful group (8.9 (7.2 to 11.3 ) versus 8.4 (7.1 to 11.6$), P=$ 
Table 1 Clinical characteristics of patients

\begin{tabular}{|c|c|c|c|}
\hline & $\begin{array}{l}\text { Weaning } \\
\text { success } \\
n=48\end{array}$ & $\begin{array}{l}\text { Weaning } \\
\text { failure } \\
n=20\end{array}$ & $P$ \\
\hline Age (years) & 66 (59 to 73$)$ & 68 (62 to 72$)$ & 0.4 \\
\hline Gender (\% male) & $30(62.5)$ & $9(45)$ & 0.28 \\
\hline SAPS II score & 54 (48 to 62 ) & 51 (45 to 55$)$ & 0.23 \\
\hline $\begin{array}{l}\text { Duration of mechanical } \\
\text { ventilation (days) }\end{array}$ & 5.0 (3.0 to 8.5$)$ & $\begin{array}{l}9.0(4.0 \text { to } \\
12.0)\end{array}$ & 0.06 \\
\hline ICU mortality (\%) & $4(8.3)$ & $7(35.0)$ & 0.05 \\
\hline \multicolumn{4}{|l|}{ Reasons for intubation } \\
\hline Cardiac arrest & $4(8.3)$ & $1(5.0)$ & \\
\hline ARDS (\%) & $7(14.5)$ & $3(15.0)$ & \\
\hline Septic shock (\%) & $14(29.1)$ & $6(30.0)$ & \\
\hline Pneumonia (\%) & $10(20.8)$ & $2(10.0)$ & \\
\hline $\begin{array}{l}\text { Cardiogenic pulmonary } \\
\text { edema (\%) }\end{array}$ & $4(8.3)$ & $2(10.0)$ & \\
\hline Coma & $6(12.5)$ & $2(10.0)$ & \\
\hline Surgery & $3(6.2)$ & $4(20.0)$ & \\
\hline $\begin{array}{l}\text { Patients in atrial fibrillation } \\
(\%)\end{array}$ & $9(18.7)$ & $6(30.0)$ & 0.48 \\
\hline COPD history (\%) & $9(18.7)$ & $6(30.0)$ & 0.2 \\
\hline Diabete mellitus & $4(8.3)$ & $6(30.0)$ & 0.05 \\
\hline Arterial hypertension & 19 (39.6) & $14(70.0)$ & 0.04 \\
\hline $\begin{array}{l}\text { Plasma creatinine (micromol/ } \\
\text { l) }\end{array}$ & 87 (57 to 203) & $\begin{array}{l}102(53 \text { to } \\
157)\end{array}$ & 0.56 \\
\hline Hemoglobin (g/dl) & $\begin{array}{l}10.9(8.7 \text { to } \\
11.4)\end{array}$ & $\begin{array}{l}9.8(9.5 \text { to } \\
10.5)\end{array}$ & 0.65 \\
\hline Relaxation impairment, n (\%) & $17(35.4)$ & $16(80)$ & 0.0004 \\
\hline Systolic dysfunction, n (\%) & $9(18.7)$ & $4(20.0)$ & $>0.99$ \\
\hline LVEF (\%) & 55 (50 to 60$)$ & 60 (50 to 65$)$ & 0.2 \\
\hline
\end{tabular}

Data are medians ( $25^{\text {th }}$ to $75^{\text {th }}$ percentile) or numbers (\% of patients). ARDS, Acute Respiratory Distress Syndrome; COPD, Chronic Obstructive Pulmonary Disease; LVEF, Left Ventricle Ejection Fraction; SAPS II, Simplified Acute Physiologic Score
0.82). No significant variation of Ea was observed in the failed group (7 (6 to 8 ) versus 7 (6 to 8 ), $P=0.9$ ), whereas LV relaxation was enhanced in the successful group with an increase in Ea velocity (8 (7 to 10$)$ versus 10 (8 to 12$), P<0.001$ ).

\section{Predictive value of the E/Ea ratio}

The area under the ROC curve for the E/Ea ratio measured at baseline in predicting weaning failure was 0.75 $( \pm 0.07, P=0.009)$. A cut-off value more or equal to 12.6 was associated with the highest diagnostic accuracy and predicted weaning failure with a sensitivity of $60 \%$ and a specificity of $95.8 \%$; it provided a positive likelihood ratio value of 14.4 and a negative likelihood ratio of 0.42. E/Ea measured 10 minutes after starting the SBT had a greater predictive value, with an area under the ROC curve of $0.86( \pm 0.06, P<0.001)$. The cut-off value of 14.5 was associated with the highest diagnostic accuracy. This ratio predicts weaning failure with a sensitivity of $75 \%$ and a specificity of $95.8 \%$. It provided a positive likelihood ratio value of 18.0 and a negative likelihood ratio of 0.26 (Figure 3).

Reproducibility of E/Ea measurement was satisfactory with an inter-observer variability of $3.4 \%$ (1.7 to $6.5 \%$ ).

\section{Predictive value of the E/Ea ratio in patients with atrial fibrillation}

We also analyzed the diagnostic accuracy of E/Ea in predicting weaning failure in the subgroup of patients with atrial fibrillation. The area under the ROC curve for $\mathrm{E} / \mathrm{Ea}$ at baseline in predicting weaning failure was $(0.87+/-0.12, P=0.02)$ and the area under the ROC

Table 2 Clinical, biological and echocardiographic parameters measured before and during spontaneous breathing trial

\begin{tabular}{|c|c|c|c|c|c|c|}
\hline & \multicolumn{3}{|c|}{ Baseline } & \multicolumn{3}{|c|}{ Spontaneous breathing trial } \\
\hline & $\begin{array}{l}\text { Success of weaning } \\
\qquad n=48\end{array}$ & $\begin{array}{l}\text { Weaning failure } \\
n=20\end{array}$ & $P$ & $\begin{array}{l}\text { Success of weaning } \\
\qquad n=48\end{array}$ & $\begin{array}{c}\text { Weaning failure } \\
n=20\end{array}$ & $P$ \\
\hline Mean blood pressure $(\mathrm{mmHg})$ & $132(122$ to 144$)$ & 135 (125 to 135$)$ & 0.91 & 145 (131 to 155$)$ & 175 (149 to 180$)$ & 0.0007 \\
\hline Heart rate (beats/min) & 93 (79 to 106$)$ & 98 (82 to 105$)$ & 0.75 & $102(87$ to 110$)$ & 120 (106 to 122$)$ & 0.002 \\
\hline Inspiratory pressure support $\left(\mathrm{cm} \mathrm{H}_{2} \mathrm{O}\right)$ & 11 (10 to 12$)$ & 12 (10 to 13$)$ & 0.17 & 7 (7 to 7$)$ & 7 (7 to 7$)$ & $>0.99$ \\
\hline PEP $\left(\mathrm{cm} \mathrm{H}_{2} \mathrm{O}\right)$ & 5 (5 to 5$)$ & 5 (5 to 5$)$ & 0.45 & $0(0$ to 0$)$ & $0(0$ to 0$)$ & $>0.99$ \\
\hline Respiratory rate (breaths/min) & 20 (16 to 25$)$ & 28 (24 to 30$)$ & 0.0008 & 23 (19 to 28 ) & 45 (39 to 49$)$ & $<0.0001$ \\
\hline RRNT & 46 (26 to 58$)$ & 66 (55 to 78$)$ & 0.0005 & 50 (30 to 66) & 136 (130 to 156$)$ & $<0.0001$ \\
\hline Arterial pH & 7.45 (7.41 to 7.48$)$ & 7.45 (7.42 to 7.5$)$ & 0.46 & 7.45 (7.41 to 7.48$)$ & 7.43 (7.38 to 7.49$)$ & 0.27 \\
\hline $\mathrm{PAO}_{2} / \mathrm{FIO}_{2}$ & 260 (235 to 303$)$ & 214 (206 to 253$)$ & 0.02 & 227 (211 to 254$)$ & 167 (149 to 200) & 0.0002 \\
\hline $\mathrm{PCO}_{2}(\mathrm{mmHg})$ & 37 (33 to 42 ) & 38 (36 to 43 ) & 0.29 & 37 (34 to 41 ) & 43 (37 to 50 ) & 0.005 \\
\hline E wave $(\mathrm{cm} / \mathrm{sec})$ & 72 (62 to 91$)$ & 80 (67 to 108 ) & 0.14 & 80 (69 to 107) & 105 (91 to 125$)$ & 0.007 \\
\hline DTE (msec) & 215 (179 to 266$)$ & 170 (160 to 223$)$ & 0.03 & 181 (150 to 205) & 155 (128 to 180$)$ & 0.04 \\
\hline Ea $(\mathrm{cm} / \mathrm{sec})$ & 8 (7 to 10$)$ & 7 (6 to 8 ) & 0.01 & 10 (8 to 12 ) & 7 (6 to 8 ) & 0.0003 \\
\hline E/Ea & 8.9 (7.2 to 11.3$)$ & 13.4 (8.5 to 16.4$)$ & 0.001 & 8.4 (7.1 to 11.6$)$ & 15.7 (13.4 to 21.1$)$ & $<0.0001$ \\
\hline
\end{tabular}

Data are medians $\left(25^{\text {th }}\right.$ to $75^{\text {th }}$ percentile) or numbers (\% of patients). DTE, deceleration time of $\mathrm{E}$ wave; Ea, protodiastolic annulus mitral velocity; $\mathrm{E}$ wave, protodiastolic mitral velocity; PAO2/FIO2, Pressure Arterial Oxygen/Fraction Inspired Oxygen; PEP, Positive Expiratory Pressure; RR/VT, Respiratory rate/Tidal Volume 


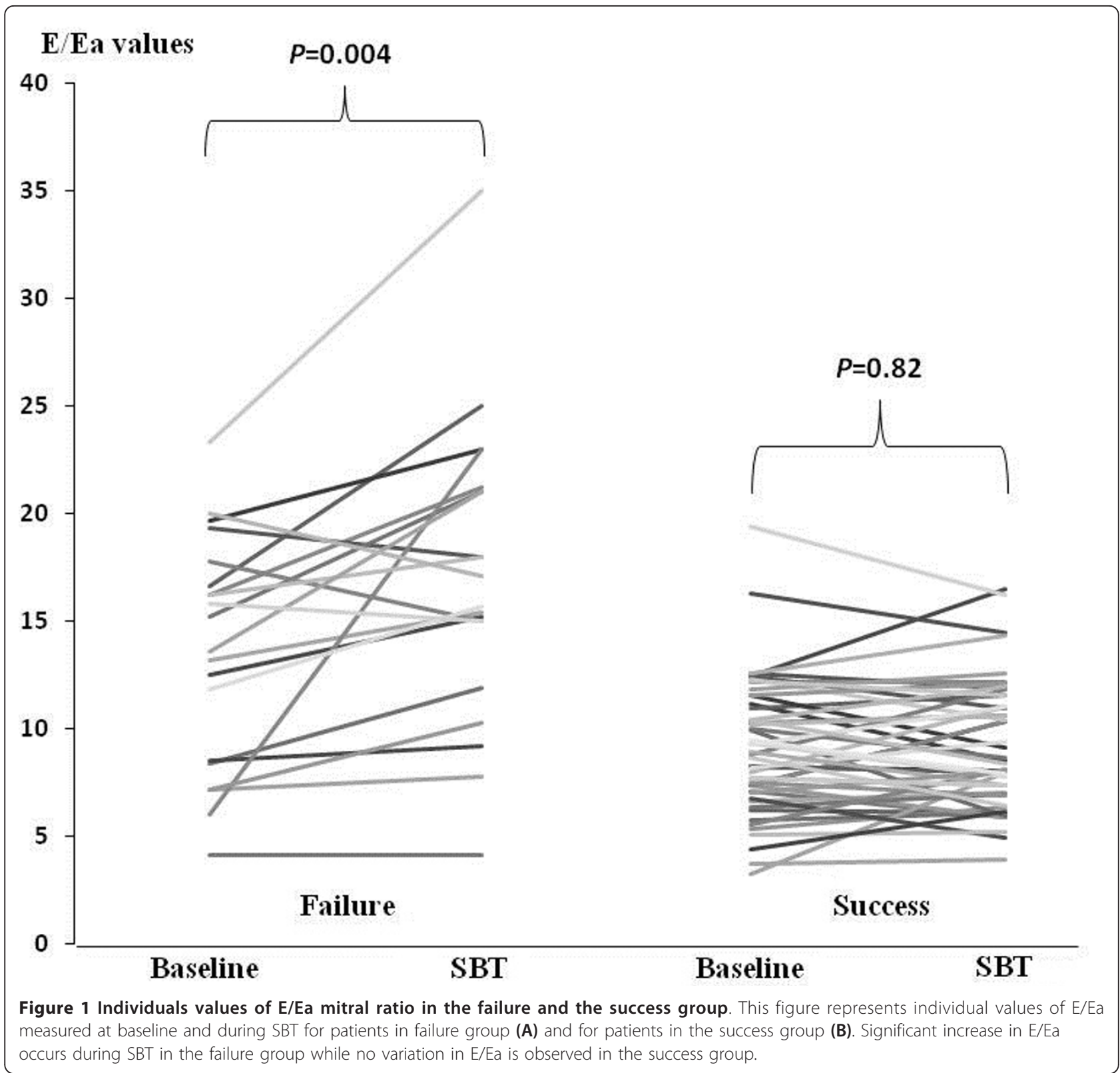

curve for $\mathrm{E} / \mathrm{Ea}$ during $\mathrm{SBT}$ in predicting weaning failure was $(0.92+/-0.07, P=0.007)$.

\section{Changes in the E/Ea ratio between consecutive SBT}

In 12 patients who had failed the first SBT, E/Ea was measured again during a second SBT. Between the two trials, 10 patients received diuretics and 2 received the angiotensin-converting enzyme inhibitor. Nine patients succeeded this second weaning trial and three failed. E/ Ea decreased in the late successful group (15.4 (11.9 to 21 ) versus 11 ( 8.9 to 13.5$), P=0.01$ ) but not in the late failed group (23 (22.1 to 24.0) versus 23 (21.9 to 23.9), $P$ $=0.18$ ).

\section{Discussion}

The major finding of this study shows that serial measurement of E/Ea accurately predicts weaning failure. E/ Ea prior to SBT was significantly higher in the failed group; however, diagnosis in predicting weaning failure, as estimated from the ROC curve was poor. Interestingly, E/Ea measured 10 minutes after starting the SBT showed better diagnostic performance; the cut-off value of 14.5 predicted weaning failure with a sensitivity of $75 \%$ and a specificity of $95.8 \%$.

Moreover, the TTE detected changes in the central hemodynamics induced by the SBT. The failed group showed a marked increase in $\mathrm{E} / \mathrm{Ea}$, whereas no 


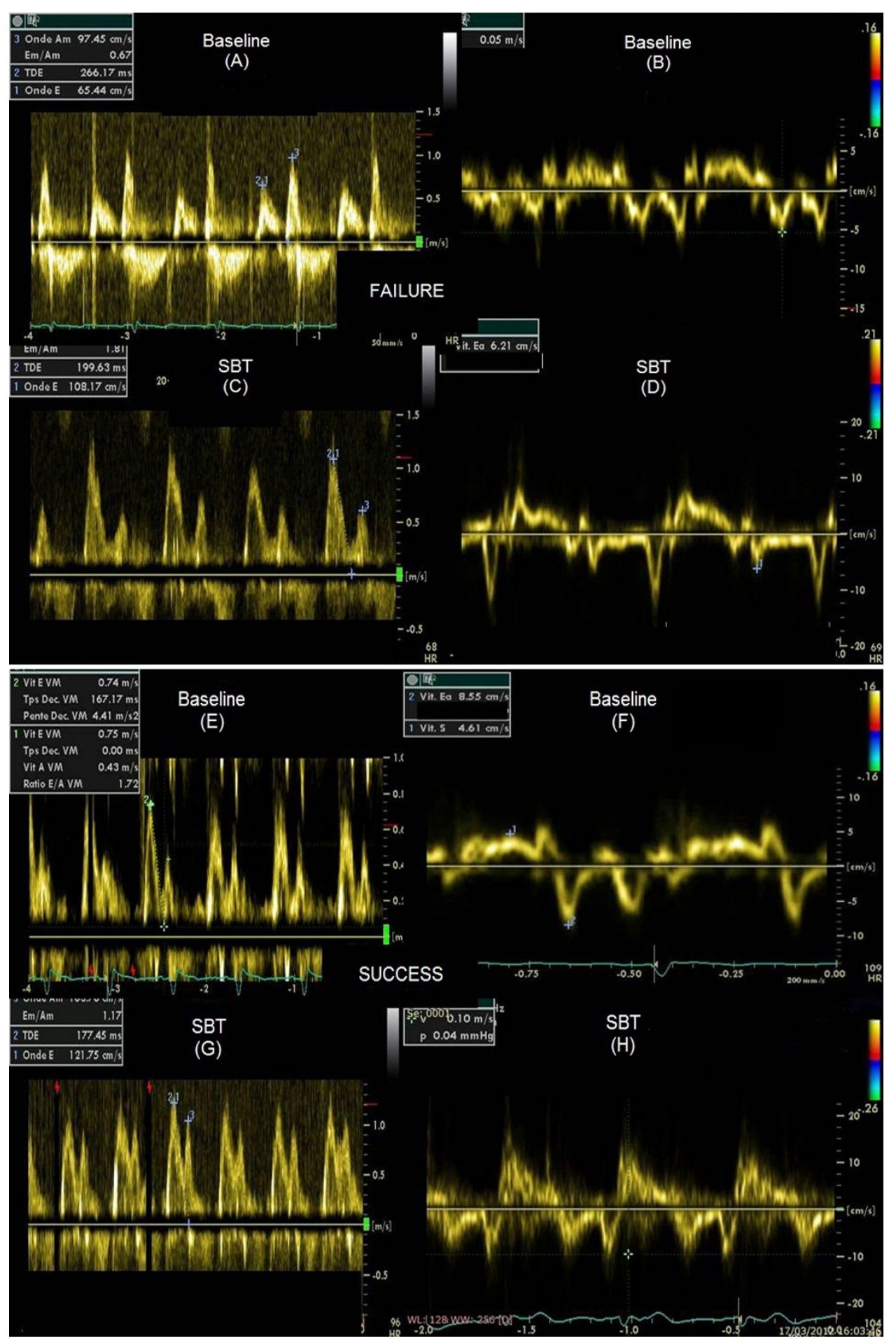

Figure 2 Doppler figure with E/Ea measurement at baseline and during SBT in success and failure. (A) Represents tissue Doppler of mitral annulus at baseline, amplitude of early diastolic wave Ea is $5 \mathrm{~cm} / \mathrm{sec}$, the resultant E/Ea ratio is 13. (B) E increases during SBT to $108 \mathrm{~cm} /$ sec. (C) Ea is $6.2 \mathrm{~cm} / \mathrm{sec}$, the resultant E/Ea increases during SBT to 17.4. (D) Represents pulsed Doppler of mitral flow at baseline in a patient who succeeded, $E$ is $74 \mathrm{~cm} / \mathrm{sec}$. (E) Ea is $8.5 \mathrm{~cm} / \mathrm{sec}$, the resultant E/Ea is 8.7. (F) E increases during SBT to $121 \mathrm{~cm} / \mathrm{sec}$. (G) In the same way Ea increases to $10 \mathrm{~cm} / \mathrm{sec}$, then E/Ea ratio remains low during SBT at 12.1 . 


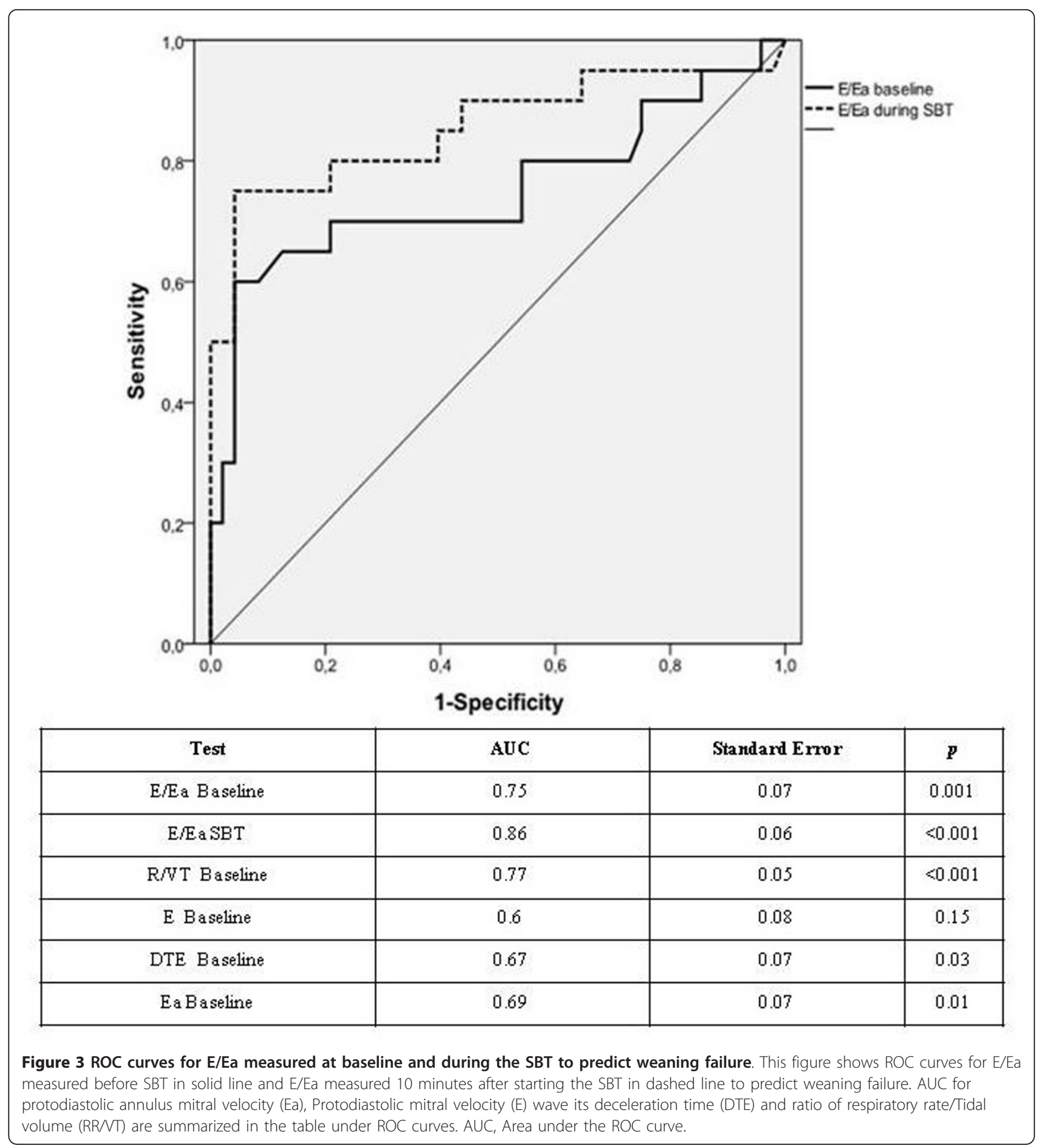

significant change was observed in the successful group. These results are suggestive of an increase in LVFP during the SBT in the sole failed group. These findings are in line with previous studies; pulmonary artery catheterization showed an increase in the pulmonary artery occlusion pressure (PAOP) during the SBT, only in patients who failed the weaning process [18].
In our study, no significant difference in the E mitral was observed at baseline between the two groups. This is explained by the fact that the E velocity or even E/A is not only determined by LVFP but also depends on ventricular factors, such as the relaxation rate, age of patients, compliance and systolic function [19]. Correlation between E/A mitral and LVFP were too weak in 
giving an accurate estimation [5]. The E/A mitral should not be used alone and must be considered in the context of the clinical picture, especially with respect to age and systolic function. These difficulties in interpreting the $\mathrm{E} / \mathrm{A}$ ratio limit its use in clinical practice. In contrast, E/Ea closely correlated with the measured invasive LVFP, even in patients under mechanical ventilation [9].

As in our study, Caille et al. found a significantly higher E/Ea prior to SBT in patients who fail, but their cut-off values for E/Ea were lower than in the present study [10]. This discrepancy is explained by a gray zone when using E/Ea alone for the estimation of the LVFP. Ommen et al. showed that an E/Ea $<8$ accurately identified patients with a normal LVFP, and E/Ea > 15 for those with an elevated LVFP [20]. For patients with intermediate values of $\mathrm{E} / \mathrm{Ea}$, between 8 and 15 , it can be difficult to accurately estimate the LVFP using only E/ Ea [20]. Lamia et al. demonstrated that the combination of $\mathrm{E} / \mathrm{A}>0.95$ mitral and $\mathrm{E} / \mathrm{Ea}>8.5$ predicted an elevation in PAOP at the end of the SBT and could then identify patients at risk of weaning failure [4]. Nevertheless, patients with atrial fibrillation exhibited a single mitral flow. Some patients present with partial or complete merging of the $\mathrm{E}$ and $\mathrm{A}$ wave due to tachycardia, despite a normal sinus rhythm. E/A could not be used in these cases and this limits its utilization for clinical practice at the bedside. Nagueh et al. demonstrated that E/Ea could be used to assess the LVFP with good accuracy in sinus tachycardia [21], even with complete merging of the $\mathrm{E}$ and $\mathrm{A}$ waves, and in the same way in patients with atrial fibrillation [12]. Patients with atrial fibrillation cannot be excluded from this study because they represent 20 to $30 \%$ of patients hospitalized in intensive care unit. Our study is the first to include such patients. For all these reasons, E/Ea seems to be the measure of choice to predict weaning failure at the bedside, especially in those with a preserved or slightly reduced LVEF, atrial fibrillation or in those with single mitral flow due to sinus tachycardia.

The second major finding of this study shows that the systolic function assessed by LVEF was not associated with weaning outcome. This is in accordance with previous studies. Mekontso et al. [22] showed, in a subgroup of patients who underwent TTE, that the LVEF did not differ between patients in the failed or in the successful group. Similar data were obtained by Lamia et al. [4] and more recently by Zapata et al. [23]. This apparent paradox is explained by the fact that in studies into cardiology, 40 to $50 \%$ of patients with typical signs of heart failure have a normal or slightly reduced LVEF [24-27]. So the LVEF is not a good predictor of clinical disability and suggests that congestive symptoms are more closely related to the diastolic properties of the ventricle than to the systolic properties $[24,25]$. The diagnosis of diastolic abnormalities can be confirmed when Doppler with tissue imaging provides evidence of impaired myocardial relaxation $[7,28,29]$. The Ea velocity constitutes a noninvasive and relatively load independent index of LV relaxation and diastolic function. Relaxation impairment is defined by an Ea velocity below or equal to 8 $\mathrm{cm} / \mathrm{sec}$ [7]. In our study, in comparison to the successful group, patients in the failed group had a lower Ea velocity and exhibited more frequent impairment in relaxation. Abnormal relaxation resulted in a prolongation of the isovolumic relaxation time with an upward shift and to the left of the diastolic pressure/volume curve (Figure 2) [24]. In such patients, a relatively small increase in the end diastolic volume may lead to an exaggerated increase in LVFP despite a normal end diastolic volume [24]. This increased sensitivity to volume changes could explain the occurrence of pulmonary edema during the SBT because an inspiratory drop in the intra-thoracic pressure tends to increase the systemic venous return and LV preload.

In our study, the evolution of the relaxation rate was also important. The failed group showed a reduced $\mathrm{Ea}$ before the SBT, and the Ea did not vary during the SBT, whereas in the successful group the Ea increased during the SBT. This finding explains why $\mathrm{E}$ wave increased during SBT in both groups. This change in mitral flow reflects an enhancement in the LV relaxation rate for the successful group while it reflects a major increase in LVFP for the failed group [30]. This is in agreement with previous studies that demonstrated that in healthy individuals the Ea velocity increased with exercise; however, in patients with abnormal relaxation and a reduced Ea velocity, the Ea did not vary with exercise or with loading conditions [31-33]. During exercise, like during the SBT, the LV filling rate could increase dramatically [31]. Normally, this increased filling occurred because the left ventricle early diastolic pressure decreased with enhanced myocardial relaxation. Thus a substantial increase in filling could occur without an increase in LVFP [32]. This normal response to exercise was lost in heart failure in patients with diastolic dysfunction who were not able to enhance relaxation with exercise [32]. In patients with impairment in relaxation, increases in $\mathrm{LV}$ filling in response to exercise were dependent on increases in LVFP [32]. Because the cardiovascular response to weaning from mechanical ventilation is similar during exercise [34], these considerations could explain the marked increase in LVFP in patients with diastolic dysfunction during the SBT. To our knowledge, this is the first study demonstrating that relaxation impairment and the inability to enhance LV relaxation during the SBT were closely associated with the risk of weaning failure. 
Our study holds several limitations. In our study, diastolic dysfunction was associated with weaning failure; however, we included a large proportion of patients with chronic obstructive pulmonary disease [35], diabetes [36], hypertensive history, and atrial fibrillation [37]; all these clinical disorders are known to be associated with diastolic dysfunction. At present, this particular population precludes generalization of our findings to all populations of intensive care units. Another limitation is the poor echocardiographic windows in some patients under mechanical ventilation; seven patients were excluded because of suboptimal images.

The diagnosis of weaning-induced pulmonary edema was made using a clinical approach; we did not assess invasive PAOP. However, the diagnosis of cardiac dysfunction during weaning is still difficult and the clinical presentation is often non-specific. In contrast, the diagnosis of weaning failure is clearly defined; this is why we chose to evaluate the utility of serial measurement of E/Ea to predict weaning failure and not the risk of cardiac dysfunction.

\section{Conclusions}

Transthoracic echocardiography with measurement of the E/Ea ratio can identify patients at risk of weaning failure at the bedside. A reduced LVEF did not seem to influence the weaning outcome, whereas diastolic abnormalities with impaired relaxation and no ability to enhance relaxation during the SBT are closely associated with weaning failure.

\section{Key messages}

- Transthoracic echocardiography with E/Ea mitral ratio predicts weaning failure at bedside even in patients with atrial fibrillation

- Left ventricle ejection fraction is not associated with weaning failure

- Diastolic properties, especially left ventricle relaxation impairment, is closely associated with weaning outcome

- The impossibility of enhancing the left ventricle relaxation rate during spontaneous breathing trial seems to be the key factor of weaning failure.

\begin{abstract}
Abbreviations
DTE: E wave deceleration time; DTI: Doppler tissue imaging; E/Ea: mitral Doppler inflow E velocity to annular tissue Doppler Ea wave velocity; Ea: early diastolic mitral annulus velocity; LV: left ventricular; LVEF: left ventricular ejection fraction; LVFP: left ventricular filling pressure; PAOP: pulmonary artery occlusion pressure; PEEP: positive end expiratory pressure; ROC: receiver operating characteristics; RR: respiratory rate; SBT: spontaneous breathing trial; TTE: transthoracic echocardiography; VT: tidal volume
\end{abstract}

\section{Author details}

${ }^{1}$ Medical Intensive Care Unit, Archet I University Hospital, 151 route Antoine de Ginestière, 06202, Nice, France. ${ }^{2}$ Department of Cardiology, Pasteur University Hospital, 30 avenue de la Voie Romaine, 06002, Nice, France.

\section{Authors' contributions}

SM and DD conceived the study protocol. SM, DD, LG, JD, HH and GB participated in the design and coordination of the study. SM and DD drafted the present manuscript. All authors read and approved the final manuscript.

\section{Competing interests}

The authors declare that they have no competing interests.

Received: 23 December 2011 Revised: 21 March 2012

Accepted: 14 May 2012 Published: 14 May 2012

\section{References}

1. Richard C, Teboul $J$, Archambaud F, Hebert JL, Michaut P, Auzepy P: Left ventricular function during weaning of patients with chronic obstructive pulmonary disease. Intensive Care Med 1994, 20:181-186.

2. Richard C, Teboul JL: Weaning failure from cardiovascular origin. Intensive Care Med 2005, 31:1605-1607

3. Lemaire F, Teboul JL, Cinotti L, Giotto G, Abrouk F, Steg G, MacquinMavier I, Zapol WM: Acute left ventricular dysfunction during unsuccessful weaning from mechanical ventilation. Anesthesiology 1988, 69:171-179.

4. Lamia B, Maizel J, Ochagavia A, Chemla D, Osman D, Richard C, Teboul J Echocardiographic diagnosis of pulmonary artery occlusion pressure elevation during weaning from mechanical ventilation. Crit Care Med 2009, 37:1696-1701.

5. Shimizu Y, Uematsu M, Shimizu H, Nakamura K, Yamagishi M, Miyatake K: Peak negative myocardial velocity gradient in early diastole as a noninvasive indicator of left ventricular diastolic function: comparison with transmitral flow velocity indices. J Am Coll Cardiol 1998 32:1418-1425.

6. Nagueh SF, Middleton KJ, Kopelen HA, Zoghbi WA, Quinones MA: Doppler tissue imaging: a noninvasive technique for evaluation of left ventricular relaxation and estimation of filling pressures. J Am Coll Cardiol 1997, 30:1527-1533.

7. Oki T, Tabata T, Yamada H, Wakatsuki T, Shinohara H, Nishikado A, luchi A, Fukuda N, Ito S: Clinical application of pulsed Doppler tissue imaging for assessing abnormal left ventricular relaxation. Am J Cardiol 1997, 79:921-928.

8. Nagueh SF, Sun H, Kopelen HA, Middleton KJ, Khoury DS: Hemodynamic determinants of the mitral annulus diastolic velocities by tissue Doppler. J Am Coll Cardiol 2001, 37:278-285.

9. Vignon P, AitHssain A, Francois B, Preux PM, Pichon N, Clavel M, Frat JP, Gastinne H: Echocardiographic assessment of pulmonary artery occlusion pressure in ventilated patients: a transoesophageal study. Crit Care 2008, 12:R18.

10. Caille V, Amiel JB, Charron C, Belliard G, Vieillard-Baron A, Vignon P: Echocardiography: a help in the weaning process. Crit Care 2010, 14:R120.

11. Arora S, Lang I, Nayyar V, Stachowski E, Ross DL: Atrial fibrillation in a tertiary care multidisciplinary intensive care unit-incidence and risk factors. Anaesth Intensive Care 2007, 35:707-713.

12. Nagueh SF, Kopelen HA, Quinones MA: Assessment of left ventricular filling pressures by Doppler in the presence of atrial fibrillation. Circulation 1996, 94:2138-2145.

13. Boles JM, Bion J, Connors A, Herridge M, Marsh B, Melot C, Pearl R, Silverman $H$, Stanchina M, Vieillard-Baron A, Welte T: Weaning from mechanical ventilation. Eur Respir J 2007, 29:1033-1056.

14. Esteban A, Alia I, Gordo F, Fernandez R, Solsona JF, Vallverdu I, Macias S, Allegue JM, Blanco J, Carriedo D, León M, de la Cal MA, Taboada F, Gonzalez de Velasco J, Palazón E, Carrizosa F, Tomás R, Suarez J, Goldwasser RS: Extubation outcome after spontaneous breathing trials with T-tube or pressure support ventilation. The Spanish Lung Failure Collaborative Group. Am J Respir Crit Care Med 1997, 156:459-465.

15. Maclntyre NR, Cook DJ, Ely EW Jr, Epstein SK, Fink JB, Heffner JE, Hess D, Hubmayer RD, Scheinhorn DJ: Evidence-based guidelines for weaning and discontinuing ventilatory support: a collective task force facilitated by the American College of Chest Physicians; the American Association for Respiratory Care; and the American College of Critical Care Medicine. Chest 2001, 120:375S-395S. 
16. Yang $\mathrm{KL}$, Tobin MJ: A prospective study of indexes predicting the outcome of trials of weaning from mechanical ventilation. $N$ Engl J Med 1991, 324:1445-1450.

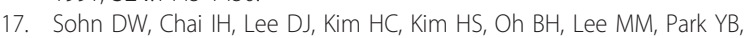
Choi YS, Seo JD, Lee YW: Assessment of mitral annulus velocity by Doppler tissue imaging in the evaluation of left ventricular diastolic function. J Am Coll Cardiol 1997, 30:474-480.

18. Jubran A, Mathru M, Dries D, Tobin MJ: Continuous recordings of mixed venous oxygen saturation during weaning from mechanical ventilation and the ramifications thereof. Am J Respir Crit Care Med 1998, 158:1763-1769.

19. Appleton CP, Hatle LK, Popp RL: Relation of transmitral flow velocity patterns to left ventricular diastolic function: new insights from a combined hemodynamic and Doppler echocardiographic study. J Am Coll Cardiol 1988, 12:426-440

20. Ommen SR, Nishimura RA, Appleton CP, Miller FA, Oh JK, Redfield MM, Tajik AJ: Clinical utility of Doppler echocardiography and tissue Doppler imaging in the estimation of left ventricular filling pressures: A comparative simultaneous Doppler-catheterization study. Circulation 2000, 102:1788-1794

21. Nagueh SF, Mikati I, Kopelen HA, Middleton KJ, Quinones MA, Zoghbi WA: Doppler estimation of left ventricular filling pressure in sinus tachycardia. A new application of tissue doppler imaging. Circulation 1998, 98:1644-1650.

22. Mekontso-Dessap A, de Prost N, Girou E, Braconnier F, Lemaire F, BrunBuisson C, Brochard L: B-type natriuretic peptide and weaning from mechanical ventilation. Intensive Care Med 2006, 32:1529-1536.

23. Zapata L, Vera P, Roglan A, Gich I, Ordonez-Llanos J, Betbese AJ: B-type natriuretic peptides for prediction and diagnosis of weaning failure from cardiac origin. Intensive Care Med 2011, 37:477-485.

24. Zile MR, Baicu CF, Gaasch WH: Diastolic heart failure-abnormalities in active relaxation and passive stiffness of the left ventricle. $N$ Engl J Med 2004, 350:1953-1959.

25. Zile MR: Heart failure with preserved ejection fraction: is this diastolic heart failure? J Am Coll Cardiol 2003, 41:1519-1522.

26. Vasan RS, Larson MG, Benjamin EJ, Evans JC, Reiss CK, Levy D: Congestive heart failure in subjects with normal versus reduced left ventricular ejection fraction: prevalence and mortality in a population-based cohort. J Am Coll Cardiol 1999, 33:1948-1955.

27. Devereux RB, Roman MJ, Liu JE, Welty TK, Lee ET, Rodeheffer R, Fabsitz RR, Howard BV: Congestive heart failure despite normal left ventricular systolic function in a population-based sample: the Strong Heart Study. Am J Cardiol 2000, 86:1090-1096.

28. Vlahovic A, Popovic AD: [Evaluation of left ventricular diastolic function using Doppler echocardiography]. Med Pregl 1999, 52:13-18.

29. Bruch C, Marin D, Kuntz S, Schmermund A, Bartel T, Schaar J, Erbel R: [Analysis of mitral annulus excursion with tissue Doppler echocardiography (tissue Doppler echocardiography = TDE). Noninvasive assessment of left ventricular, diastolic dysfunction]. Z Kardiol 1999, 88:353-362.

30. Ait-Oufella H, Tharaux PL, Baudel JL, Vandermeersch S, Meyer P, Tonnellier M, Dussaule JC, Guidet B, Offenstadt G, Maury E: Variation in natriuretic peptides and mitral flow indexes during successful ventilatory weaning: a preliminary study. Intensive Care Med 2007, 33:1183-1186.

31. Nonogi H, Hess OM, Ritter M, Krayenbuehl HP: Diastolic properties of the normal left ventricle during supine exercise. Br Heart J 1988, 60:30-38.

32. Kitzman DW, Higginbotham MB, Cobb FR, Sheikh KH, Sullivan MJ: Exercise intolerance in patients with heart failure and preserved left ventricular systolic function: failure of the Frank-Starling mechanism. J Am Coll Cardiol 1991, 17:1065-1072.

33. Ha JW, Oh JK, Pellikka PA, Ommen SR, Stussy VL, Bailey KR, Seward JB, Tajik AJ: Diastolic stress echocardiography: a novel noninvasive diagnostic test for diastolic dysfunction using supine bicycle exercise Doppler echocardiography. J Am Soc Echocardiogr 2005, 18:63-68.

34. Pinsky MR: Breathing as exercise: the cardiovascular response to weaning from mechanical ventilation. Intensive Care Med 2000, 26:1164-1166.

35. Funk GC, Lang I, Schenk P, Valipour A, Hartl S, Burghuber OC: Left ventricular diastolic dysfunction in patients with COPD in the presence and absence of elevated pulmonary arterial pressure. Chest 2008, 133:1354-1359.
36. Boyer JK, Thanigaraj S, Schechtman KB, Perez JE: Prevalence of ventricular diastolic dysfunction in asymptomatic, normotensive patients with diabetes mellitus. Am J Cardiol 2004, 93:870-875.

37. Vasan RS, Benjamin EJ, Levy D: Congestive heart failure with normal left ventricular systolic function. Clinical approaches to the diagnosis and treatment of diastolic heart failure. Arch Intern Med 1996, 156:146-157.

\section{doi:10.1186/cc11339}

Cite this article as: Moschietto et al:: Transthoracic Echocardiography with Doppler Tissue Imaging predicts weaning failure from mechanical ventilation: evolution of the left ventricle relaxation rate during a spontaneous breathing trial is the key factor in weaning outcome. Critical Care 2012 16:R81.

\section{Submit your next manuscript to BioMed Central and take full advantage of:}

- Convenient online submission

- Thorough peer review

- No space constraints or color figure charges

- Immediate publication on acceptance

- Inclusion in PubMed, CAS, Scopus and Google Scholar

- Research which is freely available for redistribution

Submit your manuscript at www.biomedcentral.com/submit
C Biomed Central 